\title{
Apresentação: TendênCias (no Brasil) DA SEmÂntica Formal das Línguas Naturais
}

O V WORKSHOP ON FoRMAL SEMANTICS AT USP

Presentation: Tendencies (in Brazil) of Formal Semantics

of Natural Languages

The V Workshop on Formal Semantics at USP

Roberta Pires de Oliveira*

À profa. Lúcia Lobato

WORKSHOPS NA USP

Os textos que compõem este dossiê foram apresentados no $V$ Workshop on Formal Semantics at USP, organizado, mais uma vez, por Ana Müller (USP), com a colaboração de Ana Scher (USP), Maria José Foltran (UFPR) e Roberta Pires de Oliveira (UFSC). Desde sua primeira versão (1999), esses workshops, sempre sob a organização e iniciativa de Müller, visam a fomentar um ambiente propício à discussão de problemas cuja explicação se encontre na semântica formal das línguas naturais, daí a sua estreita relação com a sintaxe, e mais proximamente, embora não exclusivamente, com a sintaxe gerativa. Como se tornou tradição, o workshop acontece ime- 
diatamente antes de um mini-curso ministrado por professores convidados, numa tentativa de mantermos um diálogo estreito com o que se está fazendo em semântica formal nos grandes centros de pesquisa e de ampliar nossa participação na semântica internacional.

Na versão de 2005, o workshop antecedeu o curso "The Semantics of Questions", ministrado pela profa. Venetta Dayal (Rutgers University), e contou com a participação de três palestrantes convidados: a própria Dayal, que apresentou a conferência "Cross-linguistic variation in the expression of genericity", o prof. Paul Pietrosky (University of Maryland), cuja vinda ao Brasil foi financiada pela Universidade Federal de Santa Catarina (UFSC) e o Núcleo de Epistemologia e Linguagem (NEL) desta universidade, e que proferiu palestra intitulada "Why are determiners conservative?", e a profa. Lúcia Lobato (Universidade Federal de Brasília), que discutiu o tema dos adjetivos adverbiais, na palestra "On the so-called 'adverbial uses of adjectives'”, a quem dedico este dossiê.

Nas suas primeiras edições, o número de inscritos no workshop era relativamente pequeno; neste, as organizadoras se viram obrigadas a recusar resumos por falta de espaço para todas as apresentações; além disso, tivemos que recorrer à modalidade pôster para podermos atender em particular os alunos de graduação, mas também para podermos acomodar trabalhos cuja temática ligeiramente se afastava das discussões centrais. Em 2005, foram apresentados 25 trabalhos.

Tornou-se também tradição publicar os textos do workshop na Revista Letras da Universidade Federal do Paraná (UFPR), em forma de dossiê, não apenas como uma memória do evento, mas principalmente para a divulgação do que a área tem feito e para a promoção do debate acadêmico. É este o objetivo deste dossiê, que congrega os artigos enviados para a publicação, que foram aprovados pela organização do workshop e pelo comitê editorial da revista. Esta introdução é uma leitura crítica desses textos, buscando, sempre que possível, apontar questões polêmicas.

Os ARTIGOS

É muito temerário ordenar práticas de pesquisa de um momento qualquer na história de uma disciplina, em particular porque parece haver sempre heterogeneidade e dispersão, claramente perceptíveis nas palestras, nos resumos e nos artigos do workshop - algo, é bom lembrar, imprescindível para a diversidade teórica. Mesmo sob pena de forçar generalizações, é possível identificar três tendências de pesquisa, a partir da mostra exibida 
durante o workshop: (i) as pesquisas na interface com a morfologia, que deixam clara a forte influência atual da morfologia distribuída, exemplificadas em Lemle \& França e de Medeiros; (ii) as pesquisas em que há uma estreita ligação entre semântica e sintaxe, representadas, neste dossiê, pelos artigos de Gomes, sobre quantificação nominal, e de Oliveira, sobre foco; (iii) e a semântica sobre tempo e aspecto, na qual se inserem os artigos de Gonçalves, Molsing e Bassani \& Scher. Há ainda pesquisas "marginais", no sentido de que elas se dão nas margens, em conversas com outras disciplinas. Este é o caso dos textos de de Carvalho, de Taveira e de França et al.

O artigo de Fernando Orphão de Carvalho (UNB), "Language Phylogeny and the Evolution of Semantic Complexity", apresenta a hipótese de que a complexidade semântica, entendida como um despareamento entre sentido e som, causado por um mapeamento de muitos sentidos para uma "materialidade". Esse descompasso entre forma e sentido pode ter levado à emergência de representações gramaticais, à instauração de princípios morfológicos que forçam condensações de traços significativos. A complexidade semântica teria sido, então, a força motriz de reorganizações drásticas no sistema comunicativo. Essa é uma visão evolucionista gradual, no sentido de que as línguas humanas teriam se originado de sistemas comunicativos simples, em que haveria um pareamento estrito entre som e sentido (isto é, sem conexões gramaticais) para sistemas mais sofisticados, em que se faz necessária a intermediação da sintaxe. É preciso, então, explicar as razões dessa passagem ter ocorrido apenas na nossa espécie, e não em outros primatas.

O autor aventa a hipótese de que a complexidade semântica seria explicada por pressões relativas à "navegação social". Neste ponto, estamos a milhas de distância da visão chomskiana clássica a respeito da filogênese da linguagem humana, a despeito do fato do autor inserir seu projeto dentro do quadro da Gramática Universal. A fábula que Chomsky nos conta sobre a origem da linguagem humana, ou, mais especificamente, sobre a sintaxe, pretende se ver livre de qualquer restrição de ordem "externa", de representações do mundo exterior: a gramática universal teria surgido de um acidente genético e provocado uma ruptura que nos separou definitivamente dos outros primatas. Chomsky entende que há uma descontinuidade evolutiva, enquanto que a hipótese de Carvalho supõe um processo contínuo. Sua hipótese aproxima o gerativismo do funcionalismo, na medida em que a evolução da gramática é entendida como uma "resposta" a demandas externas, ${ }^{1}$ e não é por acaso que o autor cita Jackendoff e Damá- 
sio, entre outros. Talvez este seja um movimento perceptível na proposta minimalista e seu princípio de optimalidade, mas este é um tópico em aberto. Fica, então, a pergunta: como a hipótese de de Carvalho, que se ancora no gerativismo, se enquadra nele?

Em "I-Reference for I-Languages: The Naturalist Program in Linguistics", Taveira apresenta a hipótese teórica de que o programa naturalista da lingüística de cunho chomskiano não apenas tem lugar para uma semântica "referencial", entendida como um mecanismo de referência interna, que mapeia nós terminais de uma estrutura frasal arbórea em um domínio de representações mentais, mas que ela é necessária para que o modelo funcione enquanto uma explicação da linguagem humana. Essa hipótese é, por um lado, bastante controversa, porque, entre outros, ela redefine drasticamente o que se entende por semântica referencial, cuja base, em Frege, supõe que signos lingüísticos ganham seu valor na relação com o mundo, e, por outro lado, ela é também esperada no interior de um modelo mentalista, em que a linguagem tem interface com outros sistemas de representações internas.

Neste último caso, a questão da referência é, então, apenas deslocada para um outro nível: e as representações mentais, que constituem o domínio interno da função R.I. (referência interna), vêm de onde? Como elas são "informadas"? Uma outra maneira de perguntar é: qual o papel que a experiência no mundo tem na construção dessas representações? Taveira não parece se posicionar claramente sobre este aspecto, embora em seu texto se encontrem passagens que apontam para um "construtivismo" radical, no sentido de que essas representações não têm sua fonte no mundo exterior, mas são modeladas exclusivamente pela mente; a experiência, deste prisma, teria papel extremamente diminuto (se é que tem algum). Em sua roupagem mais radical, o idealismo clássico leva ao "solipcismo" conceitual, ou seja, cada indivíduo está confinado dentro de seu próprio mundo mental, e ao relativismo, pois não há mais como garantir que haja critérios objetivos já que eles são produtos da mente. Evidentemente Chomsky evita essas conclusões freando-as com a hipótese da universalidade genética: vivemos uma ilusão compartilhada porque essa ilusão é fruto da mente que temos, dado o aparato genético que nos constitui. São várias as questões filosóficas que aqui se colocam e discuti-las é sem dúvida um exercício importante para entendermos onde estamos quando pesquisamos. Aqueles que adotam essa visão do gerativismo, calcada em Chomsky, estão muito distantes de quaisquer das versões da filosofia analítica da linguagem. Mas certamente é possível matizar essa versão super-mentalista do gerativismo.

$O$ artigo de França et al., "Conexões Conceptuais: um estudo de ERPs sobre a inescapável sintaxe na semântica", enquadrado na psicolingüística experimental, aponta, como mostra o próprio título, para uma re- 
lação estreita entre sintaxe e semântica. Os autores apresentam os resultados de uma pesquisa com priming (o elemento ativador de um par de palavras, que tem por alvo a segunda palavra) encoberto, elaborada para investigar como as palavras se relacionam conceitualmente. $O$ experimento utiliza quatro séries de pares. Na série 1, as palavras são relacionadas através de uma única preposição; por exemplo, escola-aluno podem se concatenar através da preposição para: escola para aluno. A série 2 é constituída por pares cuja concatenação se dá através de duas preposições; por exemplo, praia-calção, cuja concatenação depende de uma estrutura mais rica, como em praia para homem de calção. Pares como cadeira-revólver aparecem na série 3. Nesta, é preciso "contar uma estória" para que as palavras possam ser relacionadas; por exemplo: meu pai subia na cadeira para guardar seu revólver. Finalmente, na última série pareia-se uma palavra como uma nãopalavra (logatoma): batata-parobo.

A pesquisa mostrou uma diferença entre, de um lado, o conjunto das séries 1 e 2 , e, de outro, o conjunto das séries 3 e 4 . Mas, mais interessante, a pesquisa aponta para uma diferença significativa no tempo de ativação e no tempo de resposta entre a série 1 , constituída por pares como escolaaluno, e a série 2, constituída de pares como praia-calção. Essa diferença não pode ser explicada pela hipótese do campo semântico, uma vez que em ambas as séries as palavras pertencem ao mesmo campo. Neste modelo não se esperaria, portanto, essa diferença entre as séries. Assim sendo, os autores explicam a diferença lançando mão da hipótese de que na série 1 as palavras se concatenam via um único "nó" sintático; por exemplo, uma única preposição poderia fazer sua junção: escola para alunos. Dado que preposições são usadas para relacionar os qualia de uma palavra (o qualis é a informação contida na definição enciclopédica de uma palavra), as palavras da série 1 manteriam uma relação mais estreita entre si. Já na série 2 , a relação entre o priming e a palavra alvo se constitui por dois "nós" preposicionais, por exemplo, praia para homens de calção. Neste caso, a relação entre as palavras é mais tênue, porque é mais dependente do discurso, não sendo explicitada na enciclopédia. Assim, a concatenação das palavras é mediada pela estrutura sintática e a complexidade estrutural explica a diferença no processamento. Estruturas sintáticas mais "simples" são mais primordiais, e mais facilmente acionadas, porque são decorrentes dos qualia.

A descrição e explicação da semântica de elementos "subatômicos" marcam a tendência dos trabalhos em morfologia distribuída, embora esse modelo trate também de expressões maiores do que a palavra, como as "frases feitas". $O$ artigo de Lemle \& França, intitulado "Arbitrariedade Saussureana em Foco" é, além de uma introdução clara à morfologia distribuída, uma discussão sobre em que momento da derivação sintática se dá a 
arbitrariedade saussureana. Em termos gerais, o modelo da morfologia distribuída entende que na computação sintática não entram palavras, mas traços abstratos sem conteúdo fonológico. As derivações que se formam a partir dos itens lexicais são cíclicas de tal sorte que fechada uma fase da derivação, ela é enviada para o componente fonológico e para a enciclopédia, o componente interpretativo.

Embora o artigo apresente diferentes exemplos de derivação, o ponto central, a questão de determinar em que momento se dá a arbitrariedade saussureana, pode ser exemplificada pela polissemia da palavra corredor: corredor ${ }_{1}$, aquele que faz deslocamento rápido, corredor $r_{2}$, passagem ligando dois ou mais compartimentos. Essas palavras têm histórias derivacionais distintas que justificam sua diferença semântica. No primeiro caso, a arbitrariedade ocorre no final da primeira fase quando a raiz se concatena com o verbalizador agentivo, o vezinho, produzindo $\{\operatorname{corr}\{$ er $\}$. Assim, a arbitrariedade é negociada no primeiro envio à enciclopédia; as demais etapas se dão, então, composicionalmente. O mesmo ocorre com o segundo item, a diferença é que neste caso a raiz não se liga a um verbalizador agentivo, mas ao traço de perfectum e a um nominalizador agentivo, eninho. Assim, o que vai para a enciclopédia é [corr [ed + or]]. Neste caso, ocorreu historicamente um processo de reanálise de tal forma que a nominalização não passa pelo verbalizador agentivo; isso ocorre porque o nome ganha tanta especificidade que perde sua relação com o verbo. Trata-se de um processo de idiomatização no nível lexical.

Este processo também ocorre em estruturas idiomáticas maiores, como em bater as botas. Na análise proposta, as expressões idiomáticas são interpretadas composicionalmente, forma que a chamada interpretação literal é um passo inevitável na derivação. Se a derivação é por fases, a primeira leitura de bater botas tem que ser composicional; a leitura idiomática, em que a expressão é sinônima de morrer, ocorre por coerção contextual. Assim, temos apenas a ilusão de que na interpretação de muitos idiomatismos, a primeira leitura é a não-composicional. Essa é, sem dúvida alguma, uma afirmação bastante controversa. O tema da necessidade de acionar ou não o sentido literal na interpretação de sentenças metafóricas tem sido muito investigado na literatura em psicolingüística e, aparentemente a questão não está resolvida. Afinal, não é tarefa fácil mostrar o que exatamente ocorre na cabeça dos falantes.

No mesmo modelo teórico, o da morfologia distribuída, se insere o artigo de de Medeiros, que, como mostra o título, "Particípio Presente no Português", relaciona aspectos morfológicos a questões aspectuais. $O$ autor vai se debruçar sobre a contribuição semântica do sufixo -nte, presente em construções aparentemente tão díspares quanto comovente e corrente. Além 
deste sufixo ocorrer tanto em adjetivos quanto em substantivos, ele estrutura dois grupos bem distintos: aquele em que as derivações vêm de um verbo, os chamados deverbais, comovente exemplifica este caso; e aquele cuja derivação é não-verbal, no sentido de que sua composição atual não comporta mais o sufixo -nte, porque este se incorporou a própria raiz, como é o caso de corrente. Entende-se, dessa forma, porque o sufixo é semanticamente vazio neste último caso: ele se tornou, por idiomatismo, parte da raiz. Já nos deverbais, este sufixo é interpretado como instanciando um nó funcional aspectual. A hipótese é que nas derivações verbais, em que a raiz se concatena com um vezinho, há um nó funcional que indica aspectualidade, mais particularmente imperfectividade.

Este é, sem dúvida alguma, um ponto controverso neste artigo: o que exatamente faz esse traço de imperfectividade? Ao discutir os adjetivos deverbais, o autor aponta que ele indicaria que o tempo do evento inclui o tempo de referência, o que certamente resulta na interpretação de que o evento ultrapassa o momento de referência, produzindo uma leitura imperfectiva, que, a despeito do que afirma o autor, não é necessariamente habitual ou reiterativa. Neste prisma, comovente, por exemplo, indica que o que comove extrapola o momento de referência. Mas, ao apresentar a análise dos substantivos deverbais, o autor parece expandir demais o que ele entende por imperfectividade, alterando a operação semântica que este sufixo realiza, já que nos substantivos não se pode aplicar o raciocínio de inclusão do tempo de referência no tempo do evento. Considere, por exemplo, a explicação do autor para absorvente: absorve sempre (negrito original) que usado. Neste caso, não há um evento propriamente falando, porque se trata de um "genérico". A questão fica mais espinhosa na explicação de substantivos como fabricante.

Uma outra questão, presente também no artigo anterior, é como termos certeza, ou ao menos evidências empíricas, de que são essas as derivações. Um exemplo talvez esclareça este ponto. De Medeiros afirma que "a corrente não é algo que corre", por isso sua derivação não passa pelo verbo e o sufixo -nte não é um nó funcional e, portanto, não há indicação aspectual. Mas, o que ocorre se um falante, como eu, entende que a corrente corre? Mesmo aquela corrente feita de elos. E se o falante entende que paciente vem de ser paciente, ter paciência, e entende que paciente é aquele que está no estado (durativo) de esperar?

Este estudo está naturalmente ligado à tendência de pesquisa sobre tempo e aspecto aqui representada pelos artigos de Molsing, Gonçalves, Bassani e Scher. No artigo "Os traços temporais e as sentenças de alternância ergativa do português brasileiro", Bassani \& Scher levantam a hipótese de uma nova restrição semântica, além das já consagradas na literatura 
(como o papel temático do objeto), para explicar a (im)possibilidade de alternância ergativa, exemplificadas abaixo:

(1) a. João encheu o balde.

b. O balde encheu.

(2) a. João construiu a casa.

b. * A casa construiu

Investigando as classes aspectuais, a partir da classificação de Smith, que acrescenta às classes vendlerianas os semelfactivos, que, nessa classificação, remetem a verbos atélicos, instantâneos e dinâmicos, como tossir e espirrar. A hipótese aventada é de que o tipo de eventualidade denotada pelo predicado interfere na possibilidade da alternância. As autoras realizam, então, uma análise minuciosa da alternância em cada uma das classes aspectuais e chegam à conclusão de que essa alternância só ocorre com achievements e accomplishments, que compartilham apenas o traço da telicidade. Daí, a hipótese de que essa propriedade seria uma restrição à alternância, que só seria possível com predicados que comportem, segundo a definição de Smith, uma mudança de estado que constitui o resultado, ou o objetivo, de um evento.

As autoras levantam, então, uma série de contra-exemplos a esta hipótese. Em primeiro lugar, sentenças prototipicamente télicas como (2a) não são passíveis da alternância, como atesta a agramaticalidade de (2b). Há ainda casos de alternância, como a apresentada em (3) que, segundo a classificação de Smith, denotam atividades, sendo, portanto atélicos, mas que podem ter alternância ergativa:

(3) a. Funcionários da prefeitura alargaram a rodovia.

b. A rodovia alargou.

A solução das autoras é indicar a necessidade de mais pesquisas. Este trabalho sugere, no entanto, uma outra hipótese: não seria a ergatividade uma maneira de expressar telicidade, para casos em que o predicado verbal não é claro quanto ao alcance de um ponto final? $?^{2}$ 
Molsing defende, em "The tense and aspect of the Present Perfect in English and Portuguese", a possibilidade de se atribuir uma mesma semântica ao Presente Perfeito no inglês e no português do Brasil, contrariando o que se acredita tradicionalmente: que os dois presentes só compartilham uma morfologia, já que em ambas as línguas o presente perfeito se compõe do verbo auxiliar no presente e o verbo principal no particípio passado, como mostram os exemplos:

(4) John has arrived early.

(5) João tem chegado cedo.

A semântica, no entanto, seria muito distinta. Afinal, intuitivamente, (4) expressa um único evento de chegada do John, apresentado como se sua chegada de alguma maneira se estendesse até o momento de fala, enquanto que em (5) há reiteração de eventos de chegada cedo de João, que ocorre recentemente. Segundo a autora, este tempo, no PB, expressa iteratividade e duração, ao passo que em inglês, ele veicula um resultativo, um experiencial, uma situação persistente, ou um passado recente; em outros termos, trata-se, no inglês, sempre de um semelfactivo, entendido agora, dentro da tradição aspectual das línguas eslavas, como indicando verbos que denotam um único evento.

Na descrição de Molsing, há, neste tempo, a contribuição do perfeito que expressa uma estrutura tempo-aspectual em que o tempo tópico (isto é, o tempo de referência) inclui o tempo de fala e é posterior ao tempo do evento. Assim, o esquema temporal está aberto, o que produz uma leitura "imperfectiva" e é indeterminado tanto quanto à relação entre o tempo do evento e o tempo de fala, quanto com relação à repetição de eventos. A autora combina essa interpretação do perfeito com a possibilidade de distinguir, tanto em inglês quanto em português, a leitura contínua da leitura não-contínua. A interpretação contínua ocorre quando certos predicados indicam que o evento se prolonga ou perdura durante um período de tempo. A leitura não-contínua surge quando certos predicados são usados para expressar situações que se repetem, repetindo eventos completos.

Eventos que ocorrem uma única vez são considerados não-contínuos, porque sua repetição é sempre possível. Nessa perspectiva, o nãocontínuo carrega uma pressuposição de que há repetição; assim, no inglês, para que o presente perfeito tenha um uso semelfactivo, ${ }^{3}$ sua condição de 
assertabilidade é de que possa haver repetição. A diferença entre essas línguas se dá, então, apenas no uso não-contínuo: em português, o uso nãomarcado não-contínuo indica que houve repetição da situação; enquanto em inglês, o uso não-marcado não-contínuo expressa que a situação ocorreu uma única vez, mas há ainda assim a possibilidade da repetição. Fica a dúvida: mas por que não há exemplos dos usos não-marcados do não-contínuo? Por que em português não temos o não-contínuo semelfactivo e viceversa para o inglês?

0 artigo "On the Semantics and Pragmatics of Present Tenses" de Gonçalves apresenta uma solução semântica e pragmática para tratar a "polissemia" do tempo presente em várias línguas, exemplificada no PB pelas sentenças de (6) a (9). Este trabalho contraria assunções basilares da semântica contemporânea, em particular o fato de que se assume, sem discussão, que o tempo primitivo, de onde os demais são derivados, é o tempo presente na leitura reportiva, exemplifica em (8).

(6) João nada. (toda quarta) - leitura habitual/reiterativa

(7) João nada (tem a capacidade de nadar) - leitura de capacidade

(8) João nada (neste momento) - leitura reportiva

(9) João nada (amanhã) - leitura futurate

Há ainda o chamado presente histórico que se enquadra no reportivo. Tendo como suporte empírico, o fato de que nas línguas consideradas a leitura reportiva é extremamente marcada, frente a não-reportiva, Gonçalves argumenta, a despeito do que a tradição propõe, que a leitura preferencial de João nada é a habitual. Ele mostra, então, que não é apenas possível produzir essas leituras combinando uma semântica do tempo presente subespecificada com princípios pragmáticos gricenianos lidos a partir da teoria da optimalidade, mas que esta alternativa é melhor, porque desenha uma semântica mais leve (sem tantos operadores), mais flexível e mais próxima da intuição do falante.

Classicamente, entende-se que no tempo presente o momento do evento coincide com o momento de fala ( $\mathrm{e}=\mathrm{n}$, onde ' $\mathrm{n}$ ' é o momento de fala e 'e', o momento do evento); o que só é possível se o evento ocorre apenas uma única vez e no momento de fala; temos, então, a leitura reportiva. A leitura habitual é derivada através da postulação de um operador genérico ou habitual. As demais leituras são também obtidas através de outros ope- 
radores. A proposta de Gonçalves dispensa esses operadores. Ele inicia propondo que a semântica do presente apenas indica que o momento do evento ultrapassa o momento de fala; isto é, seu valor default é não semelfactivo ( $\mathrm{n} \subseteq \mathrm{e})$, isto é, não se refere a um evento único. Trata-se aparentemente de uma alteração pequena na semântica do presente, mas que tem como resultado evitar o predomínio da leitura reportiva. Ela é, no entanto, insuficiente para determinar se a interpretação vai ser habitual ou reportiva; essa determinação depende da situação de fala e de qual é a melhor alternativa (a alternativa ótima), tendo como medida a interação entre os princípios pragmáticos "diga o máximo que você pode dizer" e "não diga mais do que você tem que dizer".

A solução é certamente engenhosa, mas fica sobrando responder a difícil pergunta: na proposta clássica, o presente reportivo subsidia a interpretação dos outros tempos; por exemplo, o passado é o presente reportivo que acontece anterior ao momento de fala. Como, nesta nova proposta, derivar os outros tempos? Além disso, não fica claro em que o presente se difere do presente contínuo, representado no $\mathrm{PB}$ pela perífrase estar + ndo; têm ambos a mesma semântica e sua diferença se dá apenas no ranking das alternativas?

$\mathrm{Na}$ tendência em que os problemas semânticos são pensados em relação estreita com a sintaxe, Gomes propõe, em "A chave da distributividade de todo está na análise de DPs como Measure phrases de Krifka", uma solução para o seguinte impasse: como é possível fornecer uma análise que unifique as várias instanciações de todo, exemplificadas abaixo de (10) a (12), dado que tal unificação é desejada (já que temos a intuição de que sua contribuição é sempre a mesma)?

(10) Todo país chora.

(11) Todos os países choram.

(12) Todo o país chorou.

No caso em (10) não há problema para explicarmos a distributividade, que, segundo a autora é uma característica de todo, porque ele tem um nome comum na sua restrição e este, por sua vez, tem uma denotação cumulativa que permite acessar um conjunto de indivíduos e distribuir o predicado por eles. Mas tanto em (11), quanto em (12), temos DPs e DPs denotam indivíduos. Diferentemente de um nome comum, um sintagma determinado tem uma denotação quantificada, atômica, e, portanto, não tem partes acessíveis. Assim, em (10) é claro como o predicado pode se distri- 
buir pelos indivíduos, mas não há explicação para (11) e (12), porque não há entidades para o predicador poder ser distribuído.

A solução da autora se ancora na hipótese dos sintagmas de medição extensiva (SM) de Krifka (1998), que permite aos DPs ter uma estrutura interna, com partes acessíveis. $O$ sintagma de medição extensiva não faz contagem direta de indivíduos, mas sua contagem se dá a partir de uma operação de medição de substâncias. DPs que são SM têm, portanto, duas partes: um operador de medição e uma extensão cumulativa sobre a qual ele opera. Aparentemente, ambos podem ser supridos pelo contexto. Entende-se, então, que os nomes comuns denotam massivamente e essa substância pode ser contada via uma unidade de medida, chamada de functor, uma função que toma a substância e retorna unidades dessa substância. Nesta perspectiva, a denotação de um sintagma de medição extensiva é um indivíduo estruturado em um conjunto de partes, um semi-reticulado. O SM se comporta, então, como um DP, mas um DP com estrutura interna.

Assim, nas sentenças acima, a estrutura semântica dos sintagmas encabeçados por todo é mais complexa: há sempre um functor, um medidor, que, nesses exemplos, é dado contextualmente. Note que agora se supõe que há, em (10), um determinante invisível. De qualquer modo, em (10) e (11) podemos pensar em unidades de países, já em (12) pensamos nos habitantes de um país determinado. De fato, essa análise parece permitir a unificação dos usos de todo apresentados, mas há algumas questões que incomodam. Em primeiro lugar, não é claro que DPs plurais, como os países, não tenham estrutura interna. Se adotarmos a idéia de reticulado, trata-se então de um indivíduo plural que tem, portanto, estrutura interna. Neste caso, só precisaríamos explicar (12); e não precisamos entender que há um artigo oculto em (10). Além disso, a solução proposta cria, aparentemente, uma diferença grande entre sentenças como:

(13) O cachorro está sujo.

(14) O cachorro está todo sujo.

Em (13) o DP denota um indivíduo atômico particular; já em (14) ele denota um indivíduo massivo, a substância que compõe um cachorro em particular, que é medida em partes às quais é atribuída a propriedade de estar sujo. Como justificar essa diferença? Em segundo lugar, ao menos para os meus ouvidos, ${ }^{4}$ o todo em (14) pode estar funcionando como um

4 E para de alguns outros falantes, mas esta foi uma avaliação informal. 
intensificador, denotando que o cachorro da sentença em questão situa-se num grau alto na escala da sujeira. Não seria possível, ao invés de argumentar que este todo intensificador é outro todo, pensar uma análise unificada também nesta direção?

Finalmente, o artigo de Oliveira sobre o Ibibio apresenta uma pesquisa muito mais próxima da sintaxe do que da semântica, embora o tema seja a relação entre as perguntas wh e a posição de foco. Em "Wh-phrases as evidence to focus positions in Ibibio sentences", a autora reforça sua hipótese de que, se adotarmos o sistema de parâmetros para o movimento wh, somos levados à conclusão de que os sintagmas wh em Ibibio ocorrem in situ. Porém, uma análise dessa língua mostra que os sintagmas wh podem se mover para a periferia esquerda da sentença. A autora argumenta que estes casos não são casos de movimento wh, mas casos em que o movimento ocorre para checagem do traço de foco. Este movimento só ocorre acompanhado pela partícula ké que é então interpretada como núcleo do sintagma foco. Mas há, ainda, casos em que os sintagmas wh aparecem no final das sentenças, na periferia direita da sentença, precedendo esta mesma partícula. Esses casos são explicados através da noção de movimento remanescente, evitando, dessa maneira, que este seja um movimento para checar traços de foco. A autora aponta, como objeto de estudo futuro, a hipótese de que as diferenças sintáticas do movimento dos sintagmas wh em Ibibio podem estar representando diferentes tipos de focos.

Essa breve discussão dos textos que compõem este dossiê deve ser suficiente para mostrar a heterogeneidade e amplitude da semântica formal das línguas naturais. Promover debates, aprofundar as questões, possibilitar novas entradas e maneiras de entender os problemas, é a função maior tanto do workshop quanto deste dossiê.

Florianópolis, 9 de março de 2006. 